\title{
O LUGAR DOS ESTUDOS DE LÍNGUA E LITERATURA LATINA NA FORMAÇÃO DO PROFESSOR DE PORTUGUÊS
}

\author{
Grace Freire Bandeira*
}

\begin{abstract}
RESUMO: Neste artigo, pretendemos discutir o lugar dos estudos de língua e literatura latina na formação do professor de língua portuguesa. Iniciamos refletindo em torno das referências que esse tipo de estudo recebe nos Parâmetros Curriculares Nacionais, para pôr em cotejo com experiências que outros países têm nessa área de conhecimento. Desejamos, com isso, não somente pensar a nossa prática docente como também tratar das habilidades que os alunos desenvolvem quando expostos a esta formação. Com exemplos do nosso quotidiano em sala de aula e em atividades extraclasse, damos ênfase a importantes práticas que poderão ser contempladas por nossos alunos nos níveis médio e fundamental; assim favorecendo, também, um diálogo entre a Universidade e a Sociedade.
\end{abstract}

PALAVRAS-CHAVE: Latim; Literatura latina; Parâmetro curricular; Prática docente.

\section{Considerações iniciais}

Voltar o olhar para as próprias decisões tomadas é dizer-se pessoa preocupada com o alcance de suas atitudes. Quando este alcance, então, implica a formação de outrem, o comprometimento com o que dizemos, fazemos e ensinamos não pode prescindir de responsabilidade; antes, do docente consigo mesmo e, depois, com aquele a quem ensinamos.

\footnotetext{
* Doutora em Lettras pela Universidade Federal do Paraná (2007). Professora de Língua e Literatura Latina da Faculdade de Letras da Universidade Federal do Amazonas. Coordenadora do Projeto de Pesquisa "Cartas dos séculos XIX e XX: organização de um corpus diacrônico do português registrado no Amazonas no período áureo da borracha".
} 
Quando dizemos que esta tarefa - a de ensinar - se inicia com um gesto de responsabilidade do docente com a sua própria prática, queremos dizer que o processo de ensino-aprendizagem não se faz sem que um dos seus autores (o professor) acredite no que faz, vendo relevância no seu trabalho e no diálogo imprescindível que precisa estabelecer com a sociedade na qual ele também está inserido.

É isto, ver-se também como parte da sociedade, como membro dela e não melhor do que ela. Não somos particularmente superiores porque somos professores universitários; na verdade, é o contrário: exatamente porque recebemos uma formação de prestígio - de um nível de ensino regular e sistemático dentre os mais elevados disponíveis (mestrados, doutorados, pós-doutorados, por exemplo), é que nosso trabalho se torna mais exigente. Precisa, por isso mesmo, ser comprometido com o outro - não para tomar decisões por ele, mas para ajudá-lo a agir diante das possibilidades de escolha.

Quem mais conhece do leque de saberes? Nós, principalmente nós. Não excluímos outros com uma belíssima formação que vem da vida, do quotidiano dos dias, de leituras diversas. Jamais. Eu mesma, e quantas vezes, me refugiei nos braços de minha mãe que quase nenhum saber regular tem - só estudou até a antiga quarta série primária. E ela, com uma facilidade que invejo, vinha, não raros momentos, com a melhor saída ao que eu lhe apresentava. Referimo-nos, portanto, ao conhecimento das disciplinas universitárias; isto para fazermos um recorte às nossas reflexões.

A Universidade é, sob tal perspectiva, parte (e parte importantíssima) do lugar social. Nela, passamos, em ritmo acelerado, mais tempo até do que aquele que reservamos à nossa família. É sala de aula, é reunião de inúmeras naturezas, é pesquisa, extensão, orientação, e o rol não fenece. Quer dizer, ali também é preciso exercitar formas de convivência com gestores, colegas, alunos; o que nos exige, regra geral, trabalho em conjunto, com transparência, organização e respeito.

Com tudo isso temos que nos preocupar; o que não é diferente do que deve ocorrer em outros ambientes de trabalho: a convivência precisa ser pacífica, até para poder licenciar 
o pensamento divergente. Mas digo tudo isso por quê? Porque, caros colegas (em bom vocativo), nós, docentes universitários (leia-se a docência!), somos gente.

Perdão pela digressão do momento, mas, a meu ver, nenhuma reflexão acerca de qualquer prática que envolve trabalho e relações humanas pode deixar de lado a nossa natureza - humana, não para nos desculparmos pelo que não conseguimos fazer, nem para colocar, nas fragilidades tão nossas, o conjunto dos erros que cometemos. Assim somos, frágeis homens que podem se cansar, quase enlouquecer e, não raro, adoecer.

Eu adoeci e vi o câncer (porque talvez só ele mesmo) tirar-me da correria. A decisão de hoje de 'seguir vivendo', o que aconselho em relação às grandes experiências, precisa passar pelo entendimento de que temos limites físicos e emocionais; alguns dos quais irreversíveis. É impressionante mesmo como se vive diferente depois da experiência que tive o privilégio de saborear. A vida ganha outros propósitos, a começar pela noção de amanhã: o futuro, pós malignidades mil, é um dia de cada vez. Fica o recado!

Pois bem. A Universidade é extensão da nossa casa. Foi nela, e pelas mãos de belos mestres, que eu aprendi que é perfeitamente possível (e prazeroso) pensar diferente, discordar. Para testar os argumentos, para marcar uma posição, para fazer barulho e, se for o caso, para admitir, como gente que sabe digladiar, que o outro tem (ou pode ter) razão. Só por isso - ser um importante lugar em que se aprende a pensar e a expor ideias, a Universidade ocupa (ou deve ocupar) lugar de prestígio num país que intenciona ter cidadãos que pensam o seu mundo, individual e socialmente. Esse é, pois, um exigente espaço porque requer um professor solidário - que olha e vê quem está em volta: um aluno que passa fome ('apesar' dos restaurantes universitários), que percorre longas distâncias para chegar à universidade (e pelo atraso, por vezes 'pega' falta!), que apanha de companheiro porque ousa estudar.

Chegamos, enfim, a um importante ponto da reflexão que estamos propondo: a Universidade é lugar de educadores. Em sentido etimológico, ex + duco, de 'conduzir para fora'. Quer dizer, conduzimos para além, para longe, porque nosso olhar prestigia o que é largo, amplo, de vários lados. Tarefa nada fácil e por um motivo maior: precisa ser inclusiva. 
E só assim é se for para poder falar sobre nuances, cores, opiniões, diferenças. Se não for na lida, respeitosa, com o outro que me reconheço não igual, mas com semelhanças e diferenças, onde então estará o lugar para esse exercício - o da alteridade?

De volta à 'real'. Temo, hoje, por nós, professores, que não poderemos levar à sala de aula todos os assuntos (porque há quem nos quer impor sobre o que tratar) e temo também pelas próximas gerações que não poderão discutir sobre muito. A estas caberá (ou restará) confirmar, aceitar, concordar, calar. Uma ou várias gerações de tácitas criaturas. Tacitus, -a, -um é adjetivo latino que significa calado (a), mudo, não expresso. Não me refiro ao silêncio consciente, ao calar-se para ouvir e pensar enquanto se ouve; refiro-me ao calarse no vazio dos argumentos. Que fica igualzinho aos gritos quando sem conteúdo.

Ora, triste conclusão: querem tirar de nós a pertinência social do nosso trabalho. Qual função terá o método (qualquer método) a ser aplicado a conteúdos sob censura? Nenhuma. O que informo e partilho, portanto, a seguir, é experiência possível somente se em ambiente de liberdade de expressão. Como o lugar descrito, a seguir, por Fiorin (2011, p. 7):

Um curso de Letras é o lugar onde se aprende a refletir sobre os fatos linguísticos e literários, analisando-os, descrevendo-os e explicando-os. A análise, a descrição e a explicação do fato linguístico e literário não podem ser feitas de maneira empírica, mas devem pressupor reflexão crítica bem fundamentada teoricamente. Por isso, um curso de Letras tem dois módulos, que se delinearam claramente, ao longo da história da constituição dos estudos da linguagem: a) um tem por objeto o estudo dos mecanismos da linguagem humana por meio do exame das diferentes línguas faladas pelo homem; e b) o outro tem por finalidade a compreensão do fato linguístico singular que é a literatura. Embora claramente distintos, esses dois módulos mantêm relações muito estreitas. De um lado, um literato não pode voltar as costas para os estudos linguísticos, porque a literatura é um fato de linguagem; de outro, não pode o linguista ignorar a literatura, porque ela é a arte que se expressa pela palavra; é ela que trabalha a

${ }^{1}$ Alter, altera, alterum: pronome latino que se traduz por 'o outro' (ALMENDRA; FIGUEIREDO, 1999, p. 68). 
língua em todas as suas possibilidades e nela condensam-se as maneiras de ver, de pensar e de sentir de uma dada formação social numa determinada época. (FIORIN, 2011, p. 7)

O lugar singular que se descreveu acima se constitui de um espaço de reflexão, crítica e bem fundamentada teoricamente. Com ela, o estudo das letras, nos seus fatos linguísticos e literários, serve de alicerce para se conhecerem as sociedades de muitas épocas. O que, inegavelmente, acaba por referir-se a pessoas - particularmente, alunos e professores de Cursos de Letras - que têm um lugar onde aprendem a pensar, a refletir; habilidade sem a qual não se chega ao conhecimento das línguas e de suas literaturas e, por conseguinte, dos homens e dos modos como viveram, isto é, das soluções que deram para o que a vida lhes apresentou. É deste lugar que trago notícias, mais especialmente aquelas relativas aos estudos de língua e literatura latina.

\section{Os documentos oficiais}

Nesta seção, ainda sob a atmosfera de uma vida em sociedade, trazemos as referências ao latim em documentos oficiais do Ministério de Educação do Brasil, que apontam as diretrizes do ensino em nosso país.

Reportamo-nos, inicialmente, à Lei de Diretrizes e Bases da Educação, de 1961, que trazia o latim como matéria obrigatória até aos anos de 1960, depois de quando e aos poucos, vai excluindo esse estudo da vida escolar brasileira. Em linhas gerais, assistimos, dos anos de 1960 até aos de 1980, à progressiva perda de espaço dos estudos clássicos, ou ainda, à eliminação lenta e continuada dos estudos do latim (e do grego), em todos os níveis do ensino brasileiro (ROLIM DE MOURA; GARRAFONI, 2015).

O documento Parâmetros Curriculares Nacionais, em edição de 1998, sua primeira versão, faz uma referência ao latim, em página dedicada ao ensino de línguas estrangeiras. Textualmente afirma que

Não se pode ignorar o papel relativo que línguas estrangeiras diferentes têm em momentos políticos diversos da história da humanidade (o latim na época do Império Romano) e de países específicos 
(o espanhol atualmente no Brasil). Isso afeta a função social que línguas estrangeiras específicas adquirem ao serem percebidas como sendo de mais prestígio e de mais utilidade, determinando suas inclusões nos currículos escolares. (Ministério de Educação/PCN, 1998, p. 50)

No mesmo documento, em seção sobre o ensino das artes, há uma referência à palavra "estética", unicamente para citar que é derivada do grego e que significa "sentir". Em seguida, à pagina 9, afirma-se que "na escola, a transposição didática desses estudos pode refletir o conservadorismo de pontos de vista que nada possuem de teóricos e são fundados no senso comum”.

E, em ato final com vistas à promoção de um adeus definitivo ao latim, registra-se que "no confronto de opiniões e pontos de vista fundamentados", a educação deveria voltar-se para a 'herança do agora' (sic). Na mesma seção sobre as artes, à página 185, menciona-se rapidamente a tragédia grega, sugerindo uma possível comparação com uma tragédia atual.

Vale dizer que, em seção sobre o ensino do português, não há menção ao latim (nem ao grego). No mesmo documento, no conjunto de suas orientações complementares, existe, à página 119, uma referência ao latim e ao grego: “é preciso que o aluno se familiarize com os processos de derivação por prefixação e sufixação [...], o que facilita a compreensão por meio da exploração de cognatos ou das chamadas 'palavras transparentes', isto é, aquelas de origem grega ou latina, que se assemelham ao português” (MEC/PCN, 1998, p. 119).

Na versão do ano 2000, o documento Parâmetro Curricular Nacional, dirigido também ao ensino médio, em seção dedicada à área de Linguagens, Códigos e suas Tecnologias, notadamente em capítulo sobre os 'Conhecimentos de Língua Estrangeira Moderna', menciona o latim (e o grego). Referindo-se ao ensino de idiomas, este documento traz a informação de que houve ocasião em que foi privilegiado o estudo das línguas modernas, e que, em outros momentos, "valorizou-se o conhecimento do latim e do grego e o consequente acesso à literatura clássica” (MEC/PCN, 2000, p. 25).

No documento Base Nacional Comum Curricular, de 20/12/2018, afirma-se, à página 480, em relação ao ensino fundamental e no item dedicado à disciplina de História, 
que se deve "reconhecer a importância do latim na formação das línguas vernáculas modernas". Na versão final deste mesmo documento, no entanto, não se percebe mais qualquer referência ao latim.

Essas raras menções e suas infundadas notas explicativas apontam para uma progressiva perda de espaço dos estudos de latim (e de grego clássico) no currículo escolar brasileiro. Com as justificativas de não existirem professores de formação clássica (entendase, professores de latim e de grego), ou ser o latim uma língua morta (sem que se saiba o que isso significa), ou serem as aulas de latim ministradas em método antiquado e cansativo, porque pautado na memorização de declinações, fomos relegados muitos de nós (considere-se, toda a sociedade), num primeiro momento, ao distanciamento do mundo grecoromano; depois, ao desconhecimento da nossa história e da nossa cultura. Sim, porque recepcionar os estudos clássicos significa, por consequência, ter acesso a importantes capítulos que ilustram nosso patrimônio cultural.

Um conjunto de saberes é o nosso patrimônio. Revisitando-o, dialogando com ele, promovendo as devidas adaptações impostas pela 'diversidade temporal e cultural' (VIEIRA; THAMOS, 2011, p. 7), nós acabamos por acolher as experiências do passado com vistas a qualificar nossas reflexões em torno do que o presente nos traz. No dizer de Vieira e Thamos (2011, p. 5), "não somos nós que vamos ao passado, mas é ele que, em instantes irreversíveis, atravessa o nosso cotidiano".

Um problema, uma situação não se repete, entendemos, nos moldes do passado, mas o conhecimento de seu alcance à época, de seus personagens e das circunstâncias de sua produção pode nos habilitar na lida com essas questões e suas repercussões hoje. É neste sentido que se constroi a noção de Permanência Clássica, entendida como o conjunto de "bens de cultura que a modernidade herdou do seu passado helênico-romano" (PRADO, 2011, p. 53). Eis a nossa herança, o nosso bem, o ontem que abraça o quotidiano do hoje; neste, permanecendo (per+maneo), ficando por tempo largo, perdurando.

É também tudo isso que estamos jogando fora quando nos permitimos distanciar de estudos que envolvem os clássicos latinos (e gregos). Temos, claro, muito a fazer em 
torno das formas de ensinar o latim, não negamos. Em razão disso, no entanto, marginalizar o conteúdo social, histórico, antropológico que acompanha o conhecimento dos Estudos Clássicos é extravagância irresponsável.

Em recente trabalho de iniciação científica (SOUSA, 2018), constatamos que a disciplina de Filologia Românica não é mais ofertada pelas Universidades pesquisadas (entre públicas e particulares) e que, quando uma mesma Universidade oferta Bacharelado em Latim (ou Grego Clássico) e Licenciatura em Letras, esta (a Licenciatura) não mais traz, em sua grade curricular, a disciplina de Língua Latina. De um total de 9 instituições do Brasil, 2 não trazem disciplinas relacionadas à literatura latina.

Triste constatar que existem egressos de Letras que não terão qualquer domínio sobre a história de sua própria língua, não saberão explicar a redução das conjugações verbais do latim ao português, não conhecerão o desaparecimento do gênero neutro na passagem para o português, não conhecerão nada sobre as Literaturas Latina e Grega (nenhuma palavra sobre, nenhuma emoção com, nenhum verso de Homero, Safo, Alceu, Horácio, Virgílio, Ovídio, Catulo).

Nada; e tudo a depender de outras Literaturas (Portuguesa, Brasileira, por exemplo) que terão enorme dificuldade (e trabalho!) de construir quaisquer notas intertextuais. Perdese também a perspectiva multidisciplinar porque não se construiu, com os Clássicos, um espaço de diálogo entre o ensino da língua latina e os conteúdos de outras disciplinas: dificulta-se (ou anula-se), assim, o acesso ao conhecimento de culturas de outro tempo e espaço.

Em razão dos contatos que estabelecemos com colegas da área, sabemos, felizmente, de iniciativas que lutam pela causa do latim, insistindo na relevância deste saber. Citamos, como exemplo de reflexão sobre uma forma de ensinar latim, a que nos trazem Rolim de Moura e Garraffoni (2015): sobre a experiência que apresenta o latim conjugado ao grego e a estudos literários e históricos.

Neste mesmo ensaio, os autores registram experiências que vêm de países como a Alemanha e a Holanda, "países em que o ensino do grego antigo e o do latim, mesmo 
tendo sofrido transformações consideráveis, mantêm uma posição firme nos currículos" (ROLIM DE MOURA; GARRAFONI, 2015, p. 169), fazendo, assim, referência ao espaço dos Estudos Clássicos na educação daqueles países.

Preocupação semelhante, com o ensino e a aprendizagem do latim em Portugal, vemos em Borregana (2006, p. 14), no mesmo instante em que nos oferta a sua Gramática Latina, como meio de promover o estudo do latim e de facilitar o estudo da língua portuguesa. Diz o autor que

\begin{abstract}
Ninguém poderá negar que o desinteresse pela língua latina tem provocado em Portugal não apenas uma deficiente preparação para os estudos humanísticos em geral, mas também uma acentuada degradação da aprendizagem do português, o que se manifesta sobretudo no deficiente domínio da língua materna, revelado por muitos alunos que ingressam nos cursos universitários. (BORREGANA, 2006, p. 14)
\end{abstract}

Voltando-nos novamente aos documentos oficiais do Brasil e suas rápidas passagens acerca do latim, com destaque para o trecho em que se lê a respeito do "caráter prático que deveria possuir o ensino das línguas estrangeiras vivas", nós nos deparamos com a velha pergunta sobre qual seria a utilidade de se estudar latim ou assuntos considerados inúteis para o exercício de determinadas profissões.

Sob tal circunstância, ser ou não ser útil, servir ou não servir para o trabalho, deveríamos delimitar o conteúdo a ser estudado como sendo aquele que guarda uma utilidade prática (eu nem saberia fazê-lo) e, também nesta linha, teríamos que abandonar os nossos velhos (pais, avós, amigos de idade avançada). Em tempos de desmerecimento das disciplinas de Humanas (conforme temos sabido pelos meios de comunicação que nos são contemporâneos), é preciso salientar que o ensino da ciência não contempla, entre seus debates, a inutilidade de certos conteúdos.

Visa, isso sim, não somente ao aprofundamento e ao alargamento do nosso conhecimento de mundo, mas também à formação crítica do homem-cidadão - que pergunta, 
que quer saber, que investiga, que ‘checa' o que lê. Não há, por isso, espaço no fazer científico para se alegar que existam assuntos que interessam ou que sejam mais ou menos 'adequados' ao trato escolar e/ou universitário.

\section{O lugar dos estudos de latim e de literatura latina}

Chegamos a esta seção com a percepção de que somente uma abordagem educacional que leve em conta o diálogo entre diferentes campos do conhecimento pode promover uma visão crítica. E esta, como desdobramento, pode facilitar o ensino de línguas (clássicas e modernas) e pode também construir pontes entre a Universidade, as escolas e a sociedade. As experiências de que trataremos aqui procuram contemplar essas questões.

No Museu. Órgão suplementar da Universidade Federal do Amazonas, o Museu Amazônico recebe, sob sua guarda, em 1989, o que é hoje o seu maior acervo: o acervo J. G. Araújo, constituído de Diário de Navegação, Escrituras de Seringais, contratos de trabalho, guias de embarque, coleção de letras de câmbio, livros Diário e Razão e cartas manuscritas datadas de 1877 a 1989. Estas últimas são o objeto de estudo de historiadores, geógrafos, linguistas, antropólogos, que acreditam na necessidade de experiências concretas. São pesquisadores que investem no conhecimento de questões particulares à sua área de atuação, sem ignorar que o material precisa ser socializado também a outras áreas do saber.

O trecho de carta, de 9/2/1879, a seguir, em [1], ilustra o sistema de aviamento que, por ocasião do período áureo da extração e comercialização do látex para a produção da borracha na floresta amazônica, cumpria a função de intermediar compras, vendas e representações (via procuração) entre pessoas físicas e jurídicas e a empresa J. G. Araújo (considerada a maior casa aviadora entre o final do século XIX e meados do século XX).

[1] Se não me mandares no $1^{\circ}$ Vapor o que mandei pedir, me parece que morro de fome [...] o arroz que venha 2 arrobas e o café uma do melhor ou igual ao que trouxe. Olhe os phosphoros q sejão bons mande a carne e o bacalháo que o rio está enchendo muito e não ha o que se comer. 
Colegas docentes e discentes de outros departamentos da Universidade alimentamse 'dos vapores, das notas de réis, das referências a lugares e comportamentos, dos hábitos relativos ao vestir, ao comer e beber'. E, nós das Letras, também envolvidos por essas notas sociais e humanas, ao sabor do conhecimento do modo de vida das pessoas à época, ocupamo-nos, em particular, de questões de língua e de gramática.

Um dos grupos dedica-se, especialmente, aos 'achados latinos e gregos': 'peior, occasião, infelix, phosphoros, sumamente, augmento'. As luvas, as lupas, a saída da sala de aula, a lida com documentos originais dos séculos XIX e XX, a pesquisa num museu, tudo leva a crer que esse tipo de experiência revigora a professores e alunos. E acaba por chegar também àqueles que não estão no projeto de pesquisa, porque saberão dos exemplos de metaplasmos ${ }^{2}$ nas disciplinas de História da Língua, de Latim e de Grego; alcançando inclusive as aulas de sintaxe e de produção de textos, em cotejo com o modo de dizer da época de produção das cartas em estudo.

Como tratamos, na pesquisa, de variedades do latim (o clássico, o vulgar, o familiar, o eclesiástico), trazemos as questões de variação e mudança para os dados do português. Muitas disciplinas do Curso se veem retratadas na pesquisa e passam a se interessar pelo corpus em estudo. Um projeto de natureza multidisciplinar, como esse a que fizemos referência, tem despertado interesse dos nossos alunos em assuntos relacionados à língua e à literatura latinas; o que atestam os muitos trabalhos de conclusão de curso e projetos de iniciação científica com temas da área de clássicas.

Tem crescido também o conjunto dos estudos pertinentes a registros do português arcaico, nos moldes daqueles desenvolvidos por Mattos e Silva (2006). A área, ainda que minoritária, vê crescer, há cinco anos, a procura por estudos dessa natureza no mestrado em Letras da Universidade Federal do Amazonas; cujos reflexos são vistos na construção

\footnotetext{
${ }^{2}$ Metaplasmos é o nome dado às transformações fonéticas por que passam as línguas em seu curso de mudança. Sob o título 'Mudanças Fonéticas’, Viaro (2011, p. 127-186) descreve um a um os mecanismos fonéticos da adição, da subtração, da transposição e das transformações.
} 
de uma linha de pesquisa em língua e literatura latina nesse mesmo programa de pós-graduação. Alegra-nos poder afirmar que a cultura clássica interessa aos nossos alunos, futuros professores que poderão, a seu tempo, multiplicar experiências que dão importância à cultura das civilizações grega e romana antigas, em particular.

$\mathrm{Na}$ Manaus Latinista. Os passeios na capital - às suas igrejas, cemitérios, pontes, monumentos históricos, enfim a todo lugar com inscrições latinas - promovem mais descobertas (históricas, geográficas, étnicas etc) e, por isso mesmo, se opõem aos exercícios que dão ênfase a uma gramática fora de contextualização. As reflexões em torno das famílias de declinações (de substantivos e adjetivos) e das conjugações verbais, a título de exemplo, recepcionam uma forma de ensinar o latim que integra este saber a outros do quotidiano de alunos e professores.

As traduções, um dos propósitos do ensino do latim, passam a fazer parte das expectativas de quem deseja descobrir mais sobre pessoas, lugares, monumentos etc. O conhecimento do latim começa a figurar entre os saberes desejados por quem intenciona descobrir, desvelar a nossa cidade. Enquanto apreciam a beleza e a história de espaços urbanos, nossos alunos discutem questões relacionadas à arquitetura, à política, às religiões, às línguas e suas literaturas. Passam, em razão do valor que agora reconhecem aos espaços visitados, a criticar a falta de cuidado com alguns exemplares do nosso Patrimônio Material.

Nas dramatizações de textos latinos. A percepção de que outros espaços, além da sala de aula, podem servir também à regência de conteúdos de latim e de literatura latina tem inspirado a experiência do teatro. Além da descoberta de talentos (principalmente entre os alunos mais reservados, mais tímidos), as apresentações alcançam reflexões as mais elevadas sobre temas que, se expostos de maneira tradicional, talvez não produzissem as respostas como as que temos conseguido. ‘As Bucólicas', de Virgílio, e ‘As Metamorfoses’ (ou O Asno de Ouro), de Apuleio, são algumas das peças que já produzimos.

Temas de alcance filosófico, histórico, geográfico, humano vão, aos poucos, construindo um conhecimento sobre o repertório literário de uma época e, necessariamente, vão possibilitando que nossos alunos se aproximem da Antiguidade Clássica de maneira 
divertida. Nós todos nos divertimos com as referências que Virgílio faz, na nona Bucólica, aos voos e cantos dos pássaros, associando-os a prenúncios de bons ou maus agouros; o que, rapidamente, nos reportou às falas de nossos pais e avós que, aqui na região amazônica, tratam de um pássaro, cujo canto é associado à morte de pessoa que mora na casa sobre a qual 'a coruja rasga mortalha' voa.

Um agradável momento, também relacionado às Bucólicas, agora à décima, é o que traz a antiga prática de os apaixonados escreverem seus nomes em cascas de árvores, como lemos nos versos que se seguem: É verdade: prefiro sofrer nos bosques, entre tocas de feras, e gravar os meus amores em árvores de pouca idade: elas hão-de-crescer, crescerão os meus amores! ${ }^{3}$

Ou ainda ver-se o relato da prática de pendurar, nas árvores, os instrumentos de trabalho para significar despedida da atividade ou aposentadoria (GONÇALVES, 1996, p. 72), como nos versos da bucólica VII, a seguir, que facilmente foram associados à expressão pendurar as chuteiras, de semelhante interpretação: Ou então, se não podemos todos fazer o mesmo, a minha flauta melodiosa vai ficar aqui pendurada neste pinheiro sagrado.

Com 'quadros' como esses, o contato com o mundo antigo é facilitado. Daí em diante, as possibilidades de diálogo entre o mundo contemporâneo e o clássico se abrem em favor do conhecimento de muitas civilizações, não somente da romana.

Recomendamos, basicamente, três atividades ou três seções de desenvolvimento de temas e subtemas em linguagem teatral: a contação de histórias, o estabelecimento de intertextos ou, em certos casos, da retractatio (reformulação, complementação) e, por fim, as discussões dirigidas (questões que delimitam os conteúdos obrigatórios a tratar). Com estes procedimentos, que valorizam uma postura teórica e prática na lida do conteúdo programático da disciplina, vivenciamos uma perspectiva pedagógica que permite a compreensão de mundos (do romano, do grego, do nosso, de outros tantos) pelo diálogo que se estabelece, principalmente, entre as disciplinas de Literatura de todo o Curso.

${ }^{3}$ A tradução ao português dos versos 50-54 é de Gonçalves (1996, p. 90). 
Desta maneira, então, temas totalmente estranhos a alguns discentes ou de difícil trato por outros (inveja, morte, homossexualidade etc) revestem-se de um olhar científico e ganham a naturalidade desejável ao pesquisador que tem o compromisso de ajudar a desvelar a sociedade do seu tempo e as de outras eras.

$\mathrm{Na}$ sala de aula. Reservamos à sala de aula o conjunto das atividades relacionadas aos exercícios de tradução e de versão. Mesmo quando lidamos com textos em tradução, não abrimos mão dos originais, em latim. Sempre que possível, levamos os textos para que os alunos se apropriem das obras, atentem para a sua organização em verso ou em prosa, sintam o texto latino, em seus aspectos artístico e acadêmico. Principalmente assim, acreditamos, em contato com textos que a Antiguidade produziu e seus discursos, nossos alunos se sentem próximos de momentos relevantes da trajetória da humanidade.

Mesmo a gramática latina, à disposição para consulta em atividades avaliativas, 'deixa de estar fragmentada' quando apresentada em frases e expressões em latim clássico. Já nos primeiros contatos com as declinações de substantivos, privilegiamos explicar cada nome relacionando-o ao seu processo de formação em latim e, assim, aproximando esse processo dos fatos linguísticos relativos à formação das palavras, por composição e derivação, em português.

Damos como exemplos deste procedimento as palavras vinagre e ônibus. Reportamo-nos a uinum + acre, para tratar da flexão em gênero de acer, acris, acre e o emprego de acre (neutro) por exigência de uinum (vinho), neutro em latim. Para que o processo de formação de 'vinagre' se conclua, não pode outro gênero de adjetivo ${ }^{4}$, a não ser o neutro (acre), lançar-se sobre o substantivo (uinum). No que diz respeito a ônibus, brincamos com o adjetivo omnis, - e e a desinência -ibus, dativo ou ablativo da terceira declinação; do que se conclui que 'ônibus' pode ser interpretado como 'para todos', isto é, de uso coletivo. Daí em diante, as correlações, principalmente as de natureza semântica, agigantam-se: onisciente, onipotente, onipresente (só para citar alguns exemplos).

${ }^{4} \mathrm{Ad}+$ iacio $=$ adjetivo, $\mathrm{o}$ que se lança para perto de. 
O que queremos com isso dizer é que todo trabalho com as línguas e suas variedades ganha em qualidade de análise se precedida de saberes sobre a origem de formas latinas (ou gregas). Os adjetivos e suas formas de superlativo são, sempre, tema para boas discussões. Quando citamos -issimus, - $a$, -um; -errimus, - $a$, -um; -illimus, - $a$, -um, notamos clara identificação com formas portuguesas, tal como em belíssimo, paupérrimo, dificílimo. Donde, inevitavelmente, surgem questões de variação em torno de paupérrimo (pauper, -eris) e pobríssimo; ou de magérrimo, macérrimo (macer, -cra, -crum) e magríssimo. Ou ainda, em relação a docíssimo e dulcíssimo (dulcis, -e); ou a respeito de muito cruel e crudelíssimo (crudelis, -e); ou sobre célere (celer, celeris, celere) e rápido. Em todos esses casos, as reflexões não deixam de tocar o latim, não existem sem o conhecimento do latim.

E mais, é esse conhecimento que vai permitir que o preconceito diante de determinadas formas menos prestigiadas se dilua e, em seu lugar, se construa uma correlação entre o presente e o passado das línguas. Quando nos defrontamos com inter (entre), ou com semper (sempre), ou então com fenestram $>$ *festra $>$ fresta, somos apresentados a dados de metátese e de hipértese (VIARO, 2011, p. 159). Nosso olhar acerca de 'sastifeito, tauba, iorgute, largato' não promove a formulação de juízo em torno de certo e errado, não discrimina quem assim se expressa. Os dados de ontem e os de hoje, na verdade, são postos lado a lado e são estudados como expressão de um mesmo movimento: a troca de posição de fonemas - no interior de uma mesma sílaba (metátese), ou envolvendo duas sílabas (hipértese).

É assim que dizemos a nossos alunos o quão importante pode ser um trabalho de pesquisa sobre as línguas que considere também descrever levando em conta, no que for possível, o conjunto de dados do passado. Conforme lemos em Kato (1996, p. 14): "Se a língua em cada fase apresenta variação entre formas velhas e formas novas, é possível buscar no presente as pistas para a língua do passado. É a sincronia a serviço da diacronia”.

São abordagens como essas que nos movem em direção a pesquisas que veem valor no estudo de várias fases da história das línguas, propiciando o encontro com formas do 
passado (mais ou menos remoto) e com aquelas ditas inovadoras. Sob tal perspectiva, seguimos demonstrando que o estudo do latim (e sua literatura) pode merecer que lhe seja reservado um espaço na formação de alunos de Cursos de Letras, também do Brasil.

\section{Considerações finais}

Inquietos que somos com a nossa prática, o que fazemos em termos de estudos de fatos linguísticos acaba por envolver a diversidade linguística, com vistas a possibilitar que nosso aluno aprenda a se posicionar sobre o que ouve, lê e escreve, especialmente quando está tratando, grosso modo, do seu objeto de estudo: a língua portuguesa do Brasil. Nas mais diversas atividades contempladas pelo Curso, deparando-se com as prescrições gramaticais, reconhecendo-se em variedades de uso da língua, descrevendo cada fase da língua como um objeto passível de sistematização em sua heterogeneidade (LABOV, 1972), pretendemos que nosso aluno possa também considerar o conteúdo das aulas de língua e literatura latina.

Nos exemplos que damos em relação ao latim, em cotejo muitas vezes com dados do nosso quotidiano, intencionamos que o discente perceba que existe relevância na pesquisa de escavações, nos termos de Tarallo (1990). Preocupamo-nos em demonstrar que estudos de natureza histórica ajudam na proposição de tendências, de rumos, de mudanças.

Temos cuidado em dizer que o percurso do latim ao português não se faz ligeiro e não está dissociado da história da coletividade que tem empregado vários modos de dizer, ao longo de não poucos séculos - tratamos das variedades do latim, tratamos das variedades do português e daquelas que podem distinguir o português do Brasil do português de Portugal, por exemplo. Como nos propõe Silva Neto (1988, p. 52), a seguir: "A história de uma língua não é um esquema rigorosamente preestabelecido, não é um problema algébrico. Não se pode partir do latim e chegar diretamente aos dias de hoje, saltando por sobre vários séculos de palpitante vida".

Com a habilidade de reconhecer-se usuário de uma língua (de suas variedades, de sua história), nosso aluno (futuro professor) terá um leque de recursos e estratégias para 
fazer abordagens, por exemplo, em torno das gramáticas da fala e da escrita. Poderá, sabedor dos usos e de usuários de um português antigo, somente para exemplificar, partir do que seu aluno já conhece para ensinar sobre contextos de uso das línguas, porque é profissional que busca o desenvolvimento da capacidade comunicativa de seus alunos.

Nesse sentido, formas como 'eu sabo', ou 'ele veve', em lugar de 'eu sei' e 'ele vive', respectivamente, somam-se ao conjunto de conhecimentos linguísticos de outras eras, tocando na percepção de que a língua é instrumento de expressão, e que, como tal, não existe em uma única variedade de língua - a prestigiada, a padrão.

Em vez de desqualificar seu aluno, o profissional que desejamos volta-se às atividades que levarão seu aluno a um ensino de gramática que

seja pertinente para a vida, possibilitando que a pessoa viva melhor porque consegue veicular pela língua os significados/sentidos que deseja e compreender melhor os significados/sentidos que chegam até ela e de que forma chegam, sendo capaz de perceber estratégias argumentativas, significativas e de relação social e cultural concretizadas no dizer. (TRAVAGLIA, 2004, p. 17-18)

Nosso aluno-professor, sob tal proposta de ensino, não somente sabe utilizar a língua e seus recursos nas mais diversas situações de interação comunicativa, como também se importa em viabilizar o conhecimento da modalidade culta, padrão, porque sabe que tal procedimento ajuda, por sua vez, na promoção social de seus alunos (CASTILHO; ELIAS, 2012).

À luz de tais preocupações (no sentido de ocupar-se antes com), afirmamos que, no nosso entender, não pode o latim (e a sua literatura) ficar de fora da formação do aluno de Letras, em particular. Uma formação linguística que seja vista como um direito do cidadão e que a ele chega, principalmente, pelas mãos da Universidade, a quem cabe

ajudar a estabelecer uma consciência, na sociedade, da importância da educação lingüística de tal forma que as pessoas, entendendo sua essencial correlação com a possibilidade de ser cidadãos de primeira categoria e de viver bem e com mobilidade dentro de uma sociedade, desejem e busquem, como um direito seu, uma boa formação linguística. (TRAVAGLIA, 2004, p. 31) 
Sob tal perspectiva, são bons profissionais, de todas as áreas (não somente os egressos de Cursos de Letras), aqueles que são competentes usuários de suas línguas, sabem se comunicar nas mais distintas e concretas situações de interação comunicativa - desde as dificuldades que angustiam os que não sabem ler ou escrever, até os dissabores que acompanham os que não sabem interpretar, nem conseguem ler nas entrelinhas.

Aos nossos alunos, a quem também damos a formação que vem do contato com os saberes greco-romanos, cumulando-os de mais e mais saberes sobre essas sociedades e sua cultura, apresentamos mais argumentos para compreender o que acontece ao seu redor, para refletir sobre suas atitudes e seus desdobramentos, suas consequências. Referindo-se a um excerto de Horácio (65-8 a.C.), Perini (2004, p. 138) mostra que, para que se compreenda devidamente o texto que toma de exemplo, é necessário reconstruir "parte do conhecimento que Horácio e seus leitores tinham como parte de sua cultura”. O autor afirma o que se segue: "E é isso mesmo: um texto só pode ser plenamente compreendido em termos da cultura que o produziu. O homem não é somente um animal social - é um animal cultural, e cada ser humano é, de certo modo, um prisioneiro de sua cultura" (PERINI, 2004, p. 138).

Provavelmente, o perfil de aluno (de cidadão) de que tratamos aqui saberá olhar para os saberes que lhe são emergentes com mais informação, com mais elementos - os que vêm de experiências do passado, que, com os devidos retoques, podem esclarecer sobre o que fazer e até sobre o que não fazer. Desta maneira dizemos que o nosso trabalho na Universidade, lugar especial de produção de saberes, acaba por refletir-se nos sujeitos (e suas práticas) na Sociedade, o que significa dizer que as disciplinas e seus métodos e procedimentos voam e, por vezes, transpõem os 'muros' das Universidades - nem sempre resolvendo problemas, mas muitas vezes ajudando a enfrentá-los.

O que pusemos à mesa, por fim, para reflexão, em favor de uma prática que considere também os estudos de língua e literatura latina, em especial na formação do professor de português, constitui condição necessária (mas não suficiente) para que professores e alunos busquem, continuamente, revestir suas ações de reflexão, de revisão, de reanálise. A 
recomendação que fazemos é uma só: que não se prive o aluno de Letras de uma formação com que se subsidiam, ainda hoje, as reflexões teóricas de diversas áreas do saber, dentre as quais, a Teoria Literária e a Linguística. O que seria de uma ou de outra sem as gramáticas antigas, sem a Poética, de Aristóteles, sem a Arte Poética, de Horácio?

\section{THE RELEVANCE OF LATIN LANGUAGE AND ITS LITERATURE IN THE EDU- CATION OF THE PORTUGUESE TEACHER}

ABSTRACT: In this paper, we intend to discuss the place of Latin language and its literature in the education of the Portuguese teacher. We begin reflecting about the references that this type of study receives in the National Curricular Parameters, to compare with experiences that other countries have in this area of knowledge. We wish, therefore, not only to think about our teaching practice but also to deal with the skills that students develop when exposed to this education. With examples from our everyday classroom and extraclass activities, we emphasize important practices that our students can contemplate at the middle and fundamental levels; thus also favoring a dialogue between the University and the Society.

KEYWORDS: Latin language; Latin literature; Curricular Parameters; Teaching practice.

\section{REFERÊNCIAS}

ALMENDRA, Maria Ana; FIGUEIREDO, José Nunes de. Compêndio de Gramática Latina. Portugal: Porto Editora, 1999.

BORREGANA, António Afonso. Gramática Latina. Lisboa, Portugal: Lisboa Editora, 2006.

CASTILHO, Ataliba Teixeira de; ELIAS, Vanda Maria. Pequena Gramática do Português Brasileiro. São Paulo: Contexto, 2012.

FIORIN, José Luiz. Introdução à Linguística. 6. ed. São Paulo: Contexto, 2011.

GONÇALVES, Maria Isabel Rebelo (introdução, tradução e notas). VIRGÍLIO. Bucólicas. Lisboa: Editorial Verbo, 1996.

KATO, Mary A. Como, o que e por que escavar? In: ROBERTS, Ian; KATO, Mary A. (Orgs.) Português Brasileiro: uma viagem diacrônica. Campinas, SP: Editora da UNICAMP, 1996. p. 13-30.

LABOV, William. Sociolinguistic Patterns. Philadelphia: University of Pennsylvania Press, 1972.

MATTOS E SILVA, Rosa Virgínia. O português arcaico: fonologia, morfologia e sintaxe. São Paulo: Contexto, 2006. 
Ministério da Educação do Brasil, Secretaria de Educação Média e Tecnológica. Disponível em http://portal.mec.gov.br. Acesso em: 25 de abril de 2019 e em 10 de maio de 2019.

PERINI, Mário A. A língua do Brasil amanhã e outros mistérios. São Paulo: Parábola Editorial, 2004.

PRADO, João Batista Toledo. Inter-relações e permanência da poética clássica. In: VIEIRA, Bruno V. G.; THAMOS, Márcio (Orgs.) Permanência Clássica: visões contemporâneas da Antiguidade greco-romana. São Paulo: Escrituras Editora, 2011. p. 51-69.

ROLIM DE MOURA, Alessandro; GARRAFFONI, Renata S. As línguas clássicas no Ensino Fundamental: considerações a partir de uma experiência recente. In: PRATA, Patrícia; FORTES, F. (Orgs). O latim hoje: reflexões sobre cultura clássica e ensino. 1. ed. Campinas: Mercado das Letras, 2015. p. 167-204.

SILVA NETO, Serafim da. História da Língua Portuguesa. 5. ed. Rio de Janeiro: Presença, 1988.

SOUSA, Bruna Karolina. O Ensino da língua latina: experiências dentro e fora do Brasil avaliação do ensino e proposta de metodologia. Projeto de Iniciação Científica - Faculdade de Letras, Universidade Federal do Amazonas, Manaus, 2018.

TARALLO, Fernando. Tempos lingüisticos: itinerário histórico da língua portuguesa. São Paulo: Editora Ática, 1990.

TRAVAGLIA, Luiz Carlos. Gramática ensino plural. 2. ed. São Paulo: Cortez, 2004.

VIARO, Mário Eduardo. Etimologia. São Paulo: Contexto, 2011.

VIEIRA, Bruno V. G.; THAMOS, Márcio (Orgs.) Permanência Clássica: visões contemporâneas da Antiguidade greco-romana. São Paulo: Escrituras Editora, 2011.

Recebido em: 14/05/2019.

Aprovado em: 25/07/2019. 